\title{
'My Five Moments': understanding a user-centred approach to hand hygiene improvement within a broader implementation strategy
}

\author{
Benedetta Allegranzi, ${ }^{1}$ Claire Kilpatrick, ${ }^{1}$ Hugo Sax,${ }^{2}$ Didier Pittet $^{3}$
}

\begin{abstract}
1 Infection Prevention and Control Technical and Clinical Hub, Department of Integrated Health Services, World Health Organization, Geneva, Switzerland

${ }^{2}$ Department of Infectious Diseases, Bern University Hospital and University of Bern, Bern, Switzerland ${ }^{3}$ Infection Control Programme, University of Geneva Hospitals and Faculty of Medicine, Geneva, Switzerland
\end{abstract}

\section{Correspondence to} Dr Benedetta Allegranzi, Infection Prevention and Control Technical and Clinical Hub, Department of Integrated Health Services, Avenue Appia, 1211 Geneva 27, World Health Organization, Geneva, Switzerland;

allegranzib@who.int

Accepted 16 December 2021

\section{SLinked}

http://dx.doi.org/10.1136/ bmjqs-2020-011911

\section{Check for updates}

(c) Author(s) (or their employer(s)) 2022. No commercial re-use. See rights and permissions. Published by BMJ.

To cite: Allegranzi $B$, Kilpatrick C, Sax H, et al. BMJ Qual Saf Epub ahead of print: [please include Day Month Year]. doi:10.1136/ bmjqs-2021-013680
Between 2006 and 2009, WHO elaborated and issued the concept of 'My Five Moments for Hand Hygiene' in healthcare $^{1-4}$ in collaboration with the pioneering infection prevention and control (IPC) research group at the University of Geneva. The primary objective of this approach is to facilitate behavioural change and prioritise hand hygiene action at the exact times needed to prevent the transmission of pathogens and avoid harm to patients and health workers during care delivery. Importantly, the Five Moments approach overcomes some relevant barriers to hand hygiene practices identified before its launch, such as long lists for hand hygiene action without any consideration of the dynamics of patient, health worker and environmental interactions. ${ }^{5}$ The originality of the concept was to take both microbial transmission risk and human factors into account, and present an effective way to clean hands at the point of care within busy health workers' schedules and empower them to understand where hand hygiene opportunities occur within their workflow.

In addition to providing a scientific background to the Five Moments, ${ }^{2}{ }^{4}$ WHO included recommendations ranked according to the United States Centers for Disease Control and Prevention/Healthcare Infection Control Practices Advisory Committee system on indications for hand hygiene within the WHO guidelines on hand hygiene in healthcare. ${ }^{3}$ Based on evidence evaluation and consensus by experts representing key stakeholders (including those in the field of IPC and practising clinicians), these recommendations were reflected in the Five Moments. Importantly, the Five Moments approach was pilot tested before publication in a wide range of countries and settings with different resources and cultures, as part of the WHO multimodal hand hygiene implementation strategy and toolkit. ${ }^{6}$ This strategy has been shown to contribute to significant hand hygiene compliance and knowledge improvement across different professional categories, as well as a reduction in healthcare-associated infections and the spread of antimicrobial resistance. ${ }^{67}$

Since then, the Five Moments have been included in numerous hand hygiene implementation and monitoring resources by $\mathrm{WHO}^{8}$ and others, ${ }^{9}$ and adopted worldwide with adaptations to different settings and interpretations of the concept. ${ }^{10}$ However, in this issue, Gould et $a l^{11}$ highlight concerns around the Five Moments, questioning its inclusiveness of stakeholders' views, easiness of implementation and adaptation and other limitations. Furthermore, feedback to WHO has suggested that it would be of added value to develop an approach to understanding where to start with the use of the WHO implementation tools, including those associated with the Five Moments, and how to adapt them to local conditions. Implementation initiatives to date have embraced the following five aspects, which are potentially key elements to help drive forward such an approach $^{12}$ and may help overcome some of the concerns expressed by Gould et $a .^{11}$

\section{ADAPTATIONS}

Adaptations to local contextual factors and a range of situations are known to contribute significantly to successful 


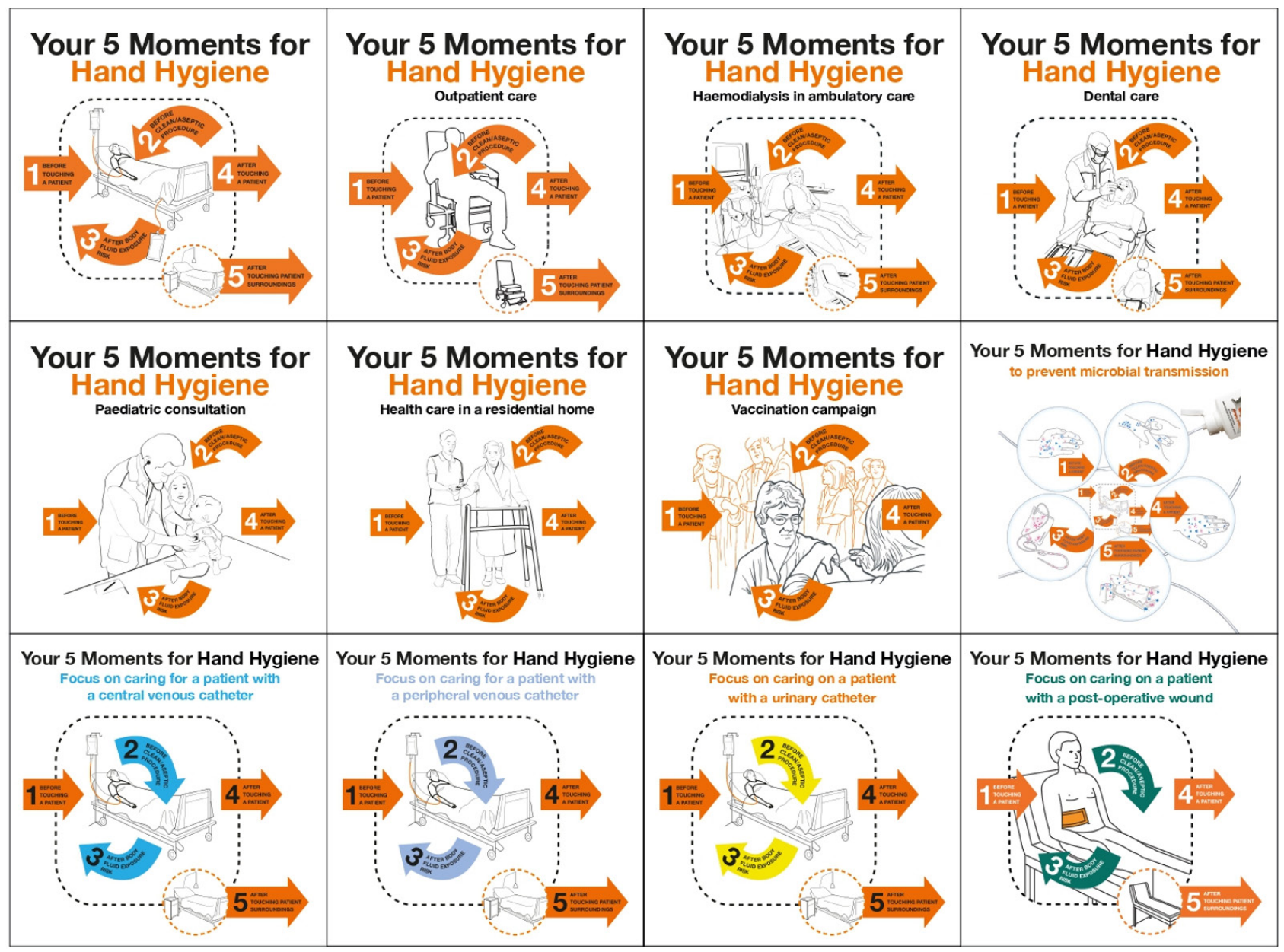

Figure 1 'My Five Moments': a flexible and user-centred approach to hand hygiene in healthcare adopted on a global scale.

implementation and adoption as part of routines. ${ }^{13}$ To address some of the limitations of the original approach and provide examples of the application of hand hygiene principles in frequently occurring care situations, WHO has developed several adaptations of the Five Moments to different settings, notably where the patient zone location changes from the bedside to other areas where the surroundings coincide with the general care environment, such as when a patient is sitting on a chair (figure 1$)^{8}$

\section{TAILORING TO FIT PATIENT CARE NEEDS}

With input by professionals from other disciplines, the Five Moments have also been tailored to the type of care delivered, such as surgical, maternal or neonatal care (figure 1), ${ }^{8}$ including long-term care and outpatient settings, such as dialysis, physiotherapy and vaccination clinics (figure 1). ${ }^{14}$ This is particularly useful to help embed hand hygiene within the patient journey and represents the gold standard to ensure that IPC practices are at their most effective level to prevent harm and considered as an integral part of daily routines. The flexibility and adaptability of the patient zone as defined by WHO and the Five Moments approach have also been demonstrated by Salmon et al in overcrowded settings with low resources where there may be more than one patient per bed. ${ }^{15}$

\section{TRANSLATIONS AND ADOPTIONS}

While it is impossible to determine the exact number of countries and facilities using the Five Moments and related adaptations and translations in different languages and dialects, we do know that it has been adopted nationwide in many countries. ${ }^{89}$ As of 4 August 2021, >25000 healthcare facilities in 184 countries were registered in the SAVE LIVES: Clean Your Hands global campaign database as a sign of their adherence to WHO hand hygiene promotion strategies, with the central pillar being the Five Moments approach at the point of care. ${ }^{8}$ As a leading example, Australia adopted it for hand hygiene promotion, practices and regular assessments in all public and private facilities countrywide for many years and reported a dramatic impact on compliance improvement and Staphylococcus aureus healthcare-associated infections reduction. ${ }^{16}$ Additionally, it has been shown that innovative training strategies facilitate its local and sustained adoption, such as 'Train-The-Trainers' programmes, regularly organised all around the world to promote its implementation and help adapt the WHO multimodal strategy if needed. ${ }^{17}$ 
WHO is particularly attentive to encourage innovations, such as non-touch dispensers, automatic monitoring systems and other technologies taking human factors and ergonomics into account, and more sophisticated adult learning educational approaches to facilitate uptake, such as gaming and augmented reality applications.

\section{HAND HYGIENE INFRASTRUCTURE CHANGE}

Gould et al propose the implementation of hand hygiene dispensers accompanied by prompts, publicity and signage throughout hospitals, clinics and wards as one of the solutions to overcome barriers to behavioural change in hand hygiene. ${ }^{11}$ We strongly agree with this suggestion that coincides with two core elements of the WHO improvement strategy: (1) 'system change'-aimed at achieving continuous availability of the necessary infrastructure, materials and equipment to enable prompt and effective hand hygiene practices at the point of care (ie, alcohol-based handrub, continuous supplies of safe, clean water, soap, single-use towels and an adequate number of functioning sinks) and (2) 'reminders in the workplace/communications', such as posters, stickers, visual and vocal prompts, for health workers, patients and visitors. Regarding the recommendation by Gould et $a l^{11}$ to place dispensers at hospital, clinic and ward entrances, WHO recently issued specific recommendations on the placement of hand hygiene stations at entrances to buildings, including hospitals, as part of crucial IPC measures in the context of the COVID-19 pandemic. ${ }^{18}$ However, the prioritisation of entrances is worthy of further debate, given that the critical place where hand hygiene action mostly protects patient and health workers from healthcare-associated infections is the point of care where the Five Moments apply. At present, we are unaware of any specific published evidence on the effect of performing hand hygiene at healthcare facility entrances.

\section{MONITORING AND FEEDBACK APPROACHES}

Enhancing hand hygiene at the point of immediate patient care requires hand hygiene evaluation, auditing and performance feedback. This is one of the critical elements of the WHO improvement strategy, which again embraces the Five Moments. Indeed, in addition to proposing methods and approaches to implement this element, ${ }^{2-468} \mathrm{WHO}$ strongly recommends hand hygiene as a key performance indicator and a minimum requirement for IPC programmes in all countries. ${ }^{19}$ WHO defined 'the point of care' as critical to hand hygiene performance and monitoring for the first time in $2006 .^{3}$ Since then, this concept has been widely promoted and it is now measured in several assessment systems, notably the WHO/UNICEF Joint Monitoring Programme for Water Supply, Sanitation and Hygiene global database. Hand hygiene action at the point of care was also the main focus of the 2021 World Hand Hygiene Day, with a range of tools made available to achieve this goal. ${ }^{20}$ Furthermore, refreshing hand hygiene training based on the local results of hand hygiene compliance (and other indicator monitoring) is another WHO recommendation, as well as an indicator to measure the level of progress of hand hygiene programmes. Finally, to comprehensively evaluate the status of hand hygiene programmes, WHO has developed and validated a Hand Hygiene Self-Assessment Framework $^{2122}$ to allow healthcare facilities to assess their current situation and develop targeted plans, thus contributing to supporting the improvement of hand hygiene at the point of care.

WHO is continuously assessing emerging hand hygiene evidence ${ }^{2324}$ in order to consider whether the recommendations contained within the 2009 guidelines should be revised and updated. For this reason, a WHO technical advisory group on hand hygiene research was recently established and meets regularly. Together with UNICEF, WHO is also leading a new initiative named Hand Hygiene for All, ${ }^{25}$ which is aimed at increasing hand hygiene investments and improvements across all sectors (eg, schools, healthcare, public places, community) in all countries. In this context and as advised by the technical advisory group, WHO will be issuing an updated version of the hand hygiene in healthcare research agenda in the very near future. In addition, a textbook entitled 'Hand hygiene: a handbook for medical professionals' including evidence and strategy updates was issued in 2016 by leading authorities in hand hygiene, including WHO staff and many experts who were part of the WHO hand guideline development group. ${ }^{24}$

Implementation strategies have been constantly enriched by new resources included in the toolkits issued every year since 2009 for World Hand Hygiene Day. ${ }^{8}$ These are always developed based on feedback from stakeholders and country users and include a range of resources for patient engagement and empowerment developed in 2013 in collaboration with leaders of patient associations. ${ }^{8}$ Of note, WHO is currently developing a new learning laboratory platform through which lessons learnt from the implementation of WHO hand hygiene strategies and other IPC approaches will be gathered from around the world, thus facilitating exchanges among users. This new project will build on implementation science principles and approaches and will include research using multiple methods. These examples of different approaches may help to explain and mitigate the concerns expressed in this issue by Gould et al. ${ }^{11}$ Unfortunately, a number of key aspects related to the Five Moments approach appear to be currently overlooked and this concurs with the perception that it may be misunderstood in some settings, despite the ongoing active efforts of WHO. Several solutions proposed by Gould et $a l^{11}$ are already supported by the WHO hand hygiene improvement strategy and many tools are already available within the above-mentioned resources. ${ }^{2-468}$ What is clear is that an understanding of, and commitment to, implementation science is 
necessary for success, representing areas that may need to be addressed in IPC teams.

\section{CONCLUSIONS}

The Five Moments approach is being constantly tailored to meet the challenges of care locations outside the traditional hospital setting, as well as across all countries and resource levels. The main thrust of the approach remains targeted at patient and health worker safety at the point of care where the risk of acquiring infection can be at its highest. Further work to help meet the Five Moments objectives through its adaptation and adoption worldwide is to be welcomed. WHO committed to further action and research on lessons learnt from field implementation, as well as the active dissemination of available tools to support countries to further understand and accept this proven approach.

Funding The authors have not declared a specific grant for this research from any funding agency in the public, commercial or not-for-profit sectors.

Disclaimer The opinions expressed in this article are those of the authors and do not reflect the official position of WHO. WHO takes no responsibility for the information provided or the views expressed in this article.

Competing interests None declared.

Patient consent for publication Not applicable.

Ethics approval This study does not involve human participants.

Provenance and peer review Commissioned; internally peer reviewed.

\section{REFERENCES}

1 World Health Organization. 'My 5 moments for hand hygiene', 2009. Available: https://www.who.int/multi-media/ details/your-5-moments-for-hand-hygiene-poster [Accessed 15 Oct 2021].

2 Sax H, Allegranzi B, Uçkay I, et al. 'My five moments for hand hygiene': a user-centred design approach to understand, train, monitor and report hand hygiene. J Hosp Infect 2007;67:9-21.

3 World Health Organization. WHO guidelines on hand hygiene in health care, 2009. Available: http://whqlibdoc.who.int/ publications/2009/9789241597906_eng.pdf [Accessed 15 Oct 2021].

4 Sax H, Allegranzi B, Chraïti M-N, et al. The world Health organization hand hygiene observation method. Am J Infect Control 2009;37:827-34.

5 Pittet D, Allegranzi B, Sax H, et al. Evidence-Based model for hand transmission during patient care and the role of improved practices. Lancet Infect Dis 2006;6:641-52.

6 Allegranzi B, Gayet-Ageron A, Damani N, et al. Global implementation of WHO's multimodal strategy for improvement of hand hygiene: a quasi-experimental study. Lancet Infect Dis 2013;13:843-51.

7 Luangasanatip N, Hongsuwan M, Limmathurotsakul D, et al. Comparative efficacy of interventions to promote hand hygiene in hospital: systematic review and network metaanalysis. BMJ 2015;351:h3278.

8 World Health Organization. Hand hygiene, 2021. Available: https://www.who.int/teams/integrated-health-services/infectionprevention-control/hand-hygiene [Accessed 26 Nov 2021].
9 Mathai E, Allegranzi B, Kilpatrick C, et al. Promoting hand hygiene in healthcare through national/subnational campaigns. J Hosp Infect 2011;77:294-8.

10 Infection and Prevention Control Canada. Hand hygiene e-learning tool, 2021. Available: https://ipac-canada.org/handhygiene-e-learning-tool.php [Accessed 15 Oct 2021].

11 Gould D, Purssell E, Jeanes A. The problem with 'My Five Moments for Hand Hygiene'. BMJ Qual Saf 2021;0:1-5.

12 Lotfinejad N, Peters A, Tartari E, et al. Hand hygiene in health care: 20 years of ongoing advances and perspectives. Lancet Infect Dis 2021;21:e209-21.

13 Greenhalgh T, Robert G, Macfarlane F, et al. Diffusion of innovations in service organizations: systematic review and recommendations. Milbank Q 2004;82:581-629.

14 World Health Organization. Hand hygiene in outpatient and home-based care and long-term care acilities: a guide to the application of the WHO multimodal hand hygiene improvement strategy and the "My 5 moments for hand hygiene" approach., 2012. Available: https://apps.who.int/iris/ handle/10665/78060 [Accessed 15 Oct 2021].

15 Salmon S, Pittet D, Sax H, et al. The 'My five moments for hand hygiene' concept for the overcrowded setting in resourcelimited healthcare systems. J Hosp Infect 2015;91:95-9.

16 Grayson ML, Stewardson AJ, Russo PL, et al. Effects of the Australian National hand hygiene initiative after 8 years on infection control practices, health-care worker education, and clinical outcomes: a longitudinal study. Lancet Infect Dis 2018;18:1269-77.

17 Tartari E, Fankhauser C, Masson-Roy S, et al. Train-theTrainers in hand hygiene: a standardized approach to guide education in infection prevention and control. Antimicrob Resist Infect Control 2019;8:206.

18 World Health Organization. Interim recommendations on obligatory hand hygiene against transmission of COVID-19, 2020. Available: https://www.who.int/publications/m/item/ interim-recommendations-on-obligatory-hand-hygiene-againsttransmission-of-covid-19 [Accessed 15 Oct 2021].

19 World Health Organization. Minimum requirements for infection prevention and control programmes, 2019. Available: https://www.who.int/infection-prevention/publications/corecomponents/en/ [Accessed 15 Oct 2021].

20 World Health Organization. World hand hygiene day 2021, 2021. Available: https://www.who.int/campaigns/world-handhygiene-day/2021 [Accessed 15 Oct 2021].

21 World Health Organization. Hand hygiene self-assessment framework, 2010. Available: https://www.who.int/gpsc/ country_work/hhsa_framework_October_2010.pdf [Accessed 15 Oct 2021].

22 Stewardson AJ, Allegranzi B, Perneger TV, et al. Testing the who hand hygiene self-assessment framework for usability and reliability. Journal of Hospital Infection 2013;83:30-5.

23 World Health Organization. Evidence of hand hygiene as the building block for infection prevention and control, 2017. Available: https://www.who.int/publications/i/item/WHO-HISSDS-2017.7 [Accessed 15 Oct 2021].

24 Pittet D, Boyce JM, Allegranzi B, eds. Hand hygiene: a handbook for medical professionals. Chichester, West Sussex, UK: John Wiley \& Sons, Inc, 2016.

25 World Health Organization. Hand hygiene for all initiative: improving access and behaviour in health care facilities, 2020. Available: https://www.who.int/publications/i/item/ 9789240011618 [Accessed 15 Oct 2021]. 